This is a self-archived - parallel published version of this article in the publication archive of the University of Vaasa. It might differ from the original.

\title{
Voltage and current THD in microgrid with different DG unit and load configurations
}

Author(s): Laaksonen, Hannu; Kauhaniemi, Kimmo

Title: $\quad$ Voltage and current THD in microgrid with different DG unit and load configurations

Year: $\quad 2008$

Version: Publisher's PDF

Copyright (C)2008 International Conference and Exhibition on Electricity Distribution CIRED

Please cite the original version:

Laaksonen, H., \& Kauhaniemi, K., (2008). Voltage and current THD in microgrid with different DG unit and load configurations . In: CIRED Seminar 2008: SmartGrids for Distribution. 23rd-24th June 2008, Frankfurt, Germany, paper 0057. https://pdfs.semanticscholar.org/ 9a9f/41f5e115af3doaea398ba941a43fc3b1151b.pdf 


\section{VOLTAGE AND CURRENT THD IN MICROGRID WITH DIFFERENT DG UNIT AND LOAD CONFIGURATIONS}

\author{
Hannu LAAKSONEN \\ University of Vaasa - Finland \\ hannu.laaksonen@uwasa.fi
}

\author{
Kimmo KAUHANIEMI \\ University of Vaasa - Finland \\ kimmo.kauhaniemi@uwasa.fi
}

\begin{abstract}
After microgrid transition from the normal operation to the islanded operation the system impedance changes considerably and it affects on the harmonic voltages of the microgrid. In this paper the voltage and current THD before and after islanding are studied with different microgrid configurations. Simulations are also made by applying negative sequence filtering in control system of converters to reduce the voltage and current THD in microgrid during unsymmetrical load. Based on the studies recommendations for technical solutions which ensure high power quality in islanded microgrid are given.
\end{abstract}

\section{INTRODUCTION}

Microgrids are distribution systems with DG units, energy storages and controllable loads, which can be operated parallel with utility grid or in an island mode (Fig. 1). Microgrid can be disconnected from the utility grid as a consequence of disturbances in the utility grid or due to planned switching events.

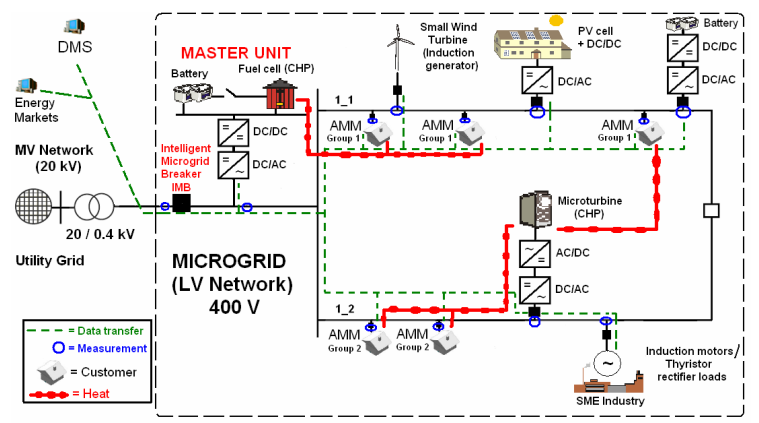

Figure 1. Example of a LV network microgrid.

An increasing demand for the reliable, high quality power and an increasing number of distorting loads have led to an increased awareness of power quality both by customers and utilities. In addition, most of the distributed generation (DG) units connected in future to low voltage (LV) network microgrids will be converter based. These DG unit converters together with possibly existing nonlinear loads have potential to distort the voltage waveform even more. This paper studies the voltage and current THD before and after islanding in the microgrid with different microgrid configurations (Fig. 1). In table 1 eight studied microgrid configurations are listed, including the reference case 1 . In reference case 1 there are converter based master unit, 2 converter based DG units and balanced passive load in microgrid. All converters are SVM (Space vector modulation) modulated with $8 \mathrm{kHz}$ switching frequency and equipped with passive LCL-filters as well as battery and dcdc converter connected to their dc-links to model the energy source. In case 1 the LV network lines of the microgrid are weak i.e. the R/X-ratio is high. Differences of each simulated cases to the reference case 1 can be seen from table 1. The studies are made with PSCAD simulation software package.

Table1. Studied microgrid configurations

\begin{tabular}{|c|c|}
\hline Case & Difference in microgrid configurations \\
\hline 1. & Reference case \\
\hline $2 \mathrm{a}$. & Lower (6 kHz) switching frequency on converters \\
\hline $2 \mathrm{~b}$. & Lower (4kHz) switching frequency on converters \\
\hline 3. & Lower R/X-ratio on LV network lines \\
\hline 4. & Thyristor rectifier (TR) load \\
\hline $5 \mathrm{a}$. & Induction motor (IM) load \\
\hline $5 \mathrm{~b}$. & Induction motor (IM) load and unbalanced passive load \\
\hline 6. & L-filters on converters \\
\hline 7. & PWM (Pulse width modulation) modulated converters \\
\hline 8. & Constant DC voltage source in the dc-link of converters \\
\hline
\end{tabular}

\section{HARMONIC DISTORTION IN MICROGRID}

Harmonic distortion in power systems is caused by nonlinear devices in which the current is not proportional to the applied voltage. The response of the power system i.e. the system impedance at each harmonic frequency determines the impact of the nonlinear load on harmonic voltage distortion. Various organizations on the national and international level have made standards both for individual and total harmonic distortion of voltage in the LV networks. For example standards IEC 61000-2-2 and EN 50160 define that the THD of the supply voltage including all harmonics up to $40^{\text {th }}$ order shall be less than $8 \%$. For distributed generation units usually more tight limits for voltage individual and total harmonic distortion are defined. These standards do not take into account the possible harmonics near the converter switching frequency (e.g. $160^{\text {th }} / 8 \mathrm{kHz}$ ). It is possible that these higher order harmonics caused by converters may resonate with the system impedance, which in turn will cause voltage waveforms with multiple zero crossings that can disturb the timing circuits etc. [1] When the microgrid transfers from the normal operation, parallel with utility grid, to the islanded operation the grid impedances and the harmonic voltages will change. Therefore, during the island operation the microgrid is much weaker and more sensitive to disturbances and especially the harmonic currents produced by converters and possible distorting loads will generate much higher harmonic voltages. To overcome possible problems during islanding 
due to high voltage and current total harmonic distortion (THD), the effect of different filter types, sizes and switching frequencies of the converters must be carefully examined. High voltage distortion can cause instability during the island operation of the microgrid and it may also interact on the converters fault-behaviour during island operation [2], [3].

The voltage and current THD (\%) results are presented in each of the studied cases with harmonics up to 255 (12.75 $\mathrm{kHz}$ ). Thus possible harmonics near the switching frequency of the DG unit converters are included in the THD values (those which are not filtered by passive filters between microgrid and DG unit converters). In this way also the possible harmonics caused by resonance between higher order harmonics coming from converters and the system impedance will be included in THD values.

\section{STUDIED SYSTEM AND SIMULATION RESULTS}

\section{Studied LV Network Based Microgrid}

The LV network used in this work is shown in Fig. 2. The system consists of one $800 \mathrm{kVA} \mathrm{MV/LV-transformer} \mathrm{which}$ normally feeds LV feeders $1 \_1$ and 1 2. In the simulation studies the islanded microgrid is disconnected from main network by the breaker so that the microgrid consists of feeders 1_1 and 1_2. At the connection point of the microgrid, before the feeders $1 \_1$ and 1_2, there is a storage unit (battery $120 \mathrm{kVA}$ ) equipped with converter 1 . At the end of feeder 1_1 there is a DG Unit $1(100 \mathrm{~kW}, 30 \mathrm{kVAr})$ equipped with converter 3 and also thyristor rectifier load (31 kW, $7 \mathrm{kVAr})$. In the middle of the feeder 1_2 there is an induction motor (51 kW, $34 \mathrm{kVAr})$ as well as DG Unit 2 $(100 \mathrm{~kW}, 30 \mathrm{kVAr})$ equipped with converter 2 at the end of the feeder.

The load in the microgrid consists of four passive loads on each feeder. The passive loads can be adjusted so that the loading of the transformer (which feeds LV feeders 1_1 and 1_2) gets some desired value between $0 \ldots 150 \%$ of the transformer ratings. In reference case 1 (table 1) loading of the transformer was set to $35 \%$ (power factor $0.98_{\text {ind }}$ ) and in different cases it was changed according to the size of the possible additional load (IM or TR).

Simulations are made in reference case 1 with higher $\mathrm{R} / \mathrm{X}$ ratio $\mathrm{LV}$ network line parameters shown in table 2 . The fault level and R/X-ratio of the feeding utility network (20 $\mathrm{kV}, 50 \mathrm{~Hz}$ ) are $200 \mathrm{MVA}$ and 0.1 respectively. The converters are modeled in reference case as three-phase, three-leg, SVM modulated units with LCL-filters and the dc-link of the master unit is modeled with battery storage + DC/DC-buck-boost converter. The dc-link voltage $\mathrm{V}_{\mathrm{DC}}$ of converter is chosen to be $0.7 \mathrm{kV}$. With all converters the PSCAD's own PLL component was used. Filter parameters used in simulations on converter based DG units are presented in table 3 .

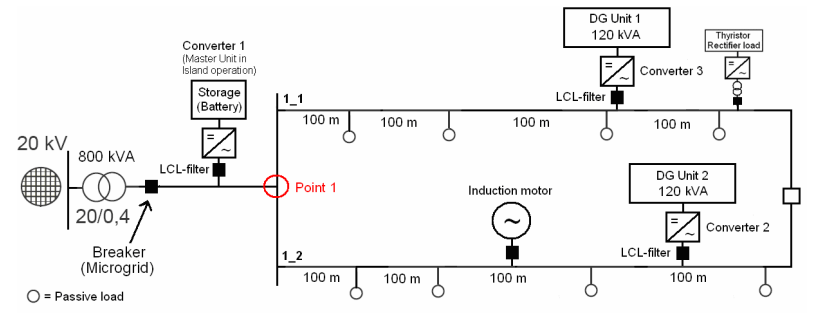

Figure 2. Studied LV network based microgrid.

Table 2. Resistance, Reactance and $\mathrm{R} / \mathrm{X}$ ratio of $\mathrm{LV}$ network in Fig. 2.

\begin{tabular}{|c|c|c|c|}
\hline & $\mathbf{R}(\mathbf{\Omega} / \mathbf{k m})$ & $\mathbf{X}(\mathbf{\Omega} / \mathbf{k m})$ & $\mathbf{R} / \mathbf{X}$ \\
\hline AMKA 3x35+50 & 0.868 & 0.104 & 8.35 \\
\hline AXMK 4x185S & 0.164 & 0.0817 & 2.01 \\
\hline
\end{tabular}

Table 3. Filter parameters used in simulations on converter based DG units.

\begin{tabular}{|c|c|c|}
\hline & Parameter & Value \\
\hline LCL-filter & $\mathrm{L}_{1}, \mathrm{R}_{\mathrm{d}}, \mathrm{C}, \mathrm{L}_{2}$ & $0.4 \mathrm{mH}, 0.1 \Omega, 10 \mu \mathrm{F}, 0.2 \mathrm{mH}$ \\
\hline L-filter & $\mathrm{L}_{1}$ & $1.6 \mathrm{mH}$ \\
\hline
\end{tabular}

\section{Single Master Operation}

During islanding, microgrid is operated in single master operation mode, which in this case means that the converter 1 with battery storage (Fig. 3 ) will act as the master unit and it has the main responsibility to control the voltage and frequency in microgrid when islanded. The control system for master unit (Battery storage) converter 1 in island operation is shown in Fig. 4. All the other DG units can then be operated in conventional PQ mode i.e. they do neither take part in frequency nor voltage control.

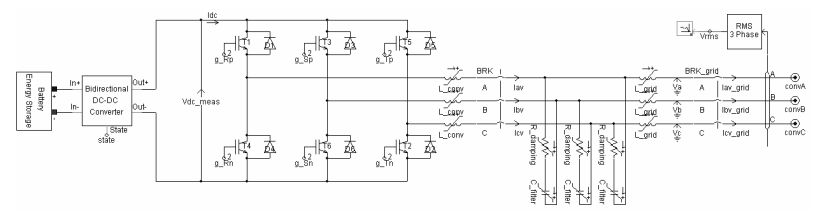

Figure 3. PSCAD simulation model of the master unit with battery storage + dc-dc buck-boost converter.

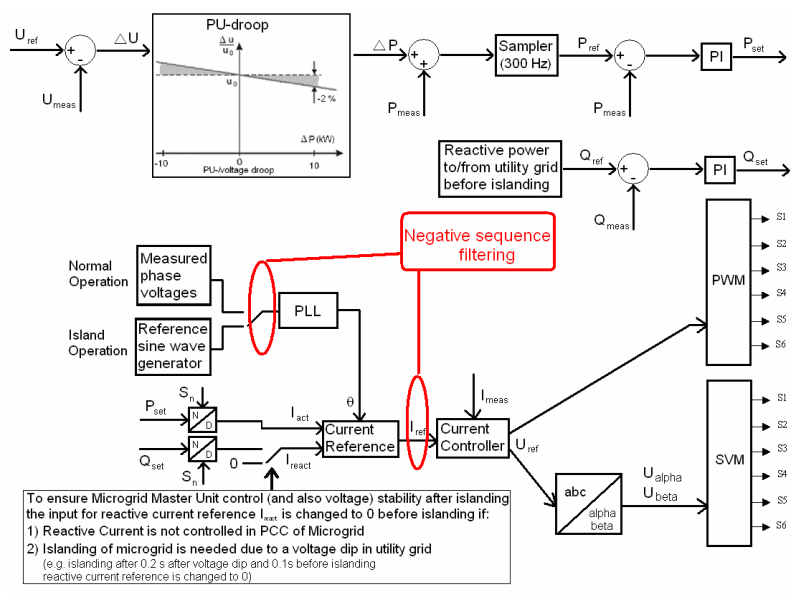

Figure 4. Control system of master unit converter during islanding. 
By using power quality compensator (PQC) with energy storage as the master unit of microgrid it could also be possible to improve the quality of currents flowing between the microgrid and the utility grid [4].

\section{$\underline{\text { Simulation results }}$}

In this section the simulation results from studies about voltage and current THD during normal and island operation of microgrid with different configurations are presented as well as the effect of negative sequence filtering on THD.

Voltage and current THD with different configurations In table 4 the voltage and current THD before and after islanding in the microgrid with different microgrid configurations (table 1). In Fig. 5 the voltage and current THD from different cases during island operation are shown as a bar graph. From table 4 can be seen that the reduction of switching frequency of converters from 8 to $4 \mathrm{kHz}$ (case $2 b$ ) increases notably the voltage harmonic distortion both in normal and island operation with the used LCL-filter parameters on converters (table 3 ). Also the effect of thyristor load (case 4) to the harmonic voltage distortion and the current THD of the DG unit converter next to it is obvious especially during island operation (Fig. 5). With PWM modulation (case 7) and with modeling the energy source as constant dc source (case 8 ) the voltage and current THD are slightly higher than in reference case 1 . The most significant increase in voltage THD during normal and especially during island operation is experienced in case 6 when L-filters are used on converters instead of LCL-filters.

Table 4. Voltage and current THD (255 harmonics) in microgrid with different configurations

\begin{tabular}{|c|c|c|}
\hline Case & $\begin{array}{c}\text { Before Islanding } \\
\left(\mathbf{U}_{\text {THD }}{ }^{*} / \mathbf{I}_{\text {THD }}{ }^{* *}\right)\end{array}$ & $\begin{array}{c}\text { During Islanding } \\
\left(\mathbf{U}_{\text {THD }}{ }^{*} / \mathbf{I}_{\text {THD }}{ }^{* *}\right)\end{array}$ \\
\hline 1. & $0.40 / 0.24$ & $1.17 / 0.26$ \\
\hline $2 \mathrm{a}$. & $0.73 / 0.36$ & $2.11 / 0.32$ \\
\hline $2 \mathrm{~b}$. & $2.00 / 1.08$ & $5.08 / 0.61$ \\
\hline 3. & $0.42 / 0.27$ & $1.17 / 0.26$ \\
\hline 4. & $0.58 / 1.23$ & $5.39 / 3.02$ \\
\hline $5 \mathrm{a}$. & $0.41 / 0.27$ & $1.16 / 0.29$ \\
\hline 6. & $2.71 / 0.7$ & $25.01 / 0.40$ \\
\hline 7. & $0.60 / 0.52$ & $1.85 / 0.43$ \\
\hline 8. & $0.44 / 0.36$ & $1.37 / 0.33$ \\
\hline
\end{tabular}

${ }^{*}$ From phase $\mathrm{C}$ in connection point of master unit, ${ }^{* *}$ From phase $\mathrm{A}$ in connection point of DG Unit 1 on feeder 1_1

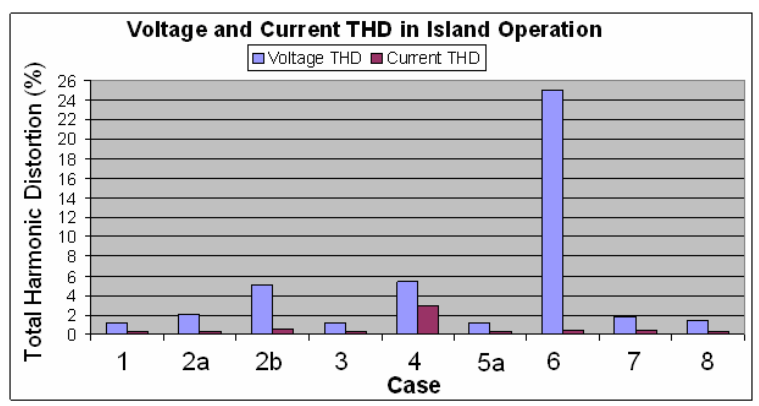

Figure 5.Voltage and current THD (\%) in different cases (from table 4) during island operation of microgrid.
With L-filter especially the higher order harmonics are not filtered out from the output current of the converters very effectively. Another reason for the high voltage THD in case 6 can be seen from Fig. 6 where the system harmonic impedance from point 1 (Fig. 2) in some cases during normal and island operation are presented. Especially during island operation the high resonance peak in case 6 near the switching frequency of converters will increase the voltage THD very significantly while the current THD is reasonably low (table 4).

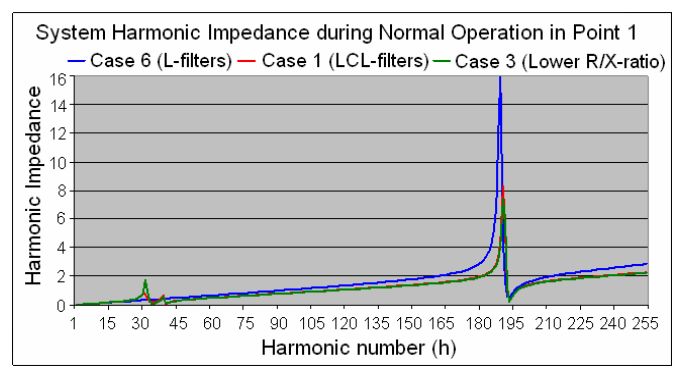

a)

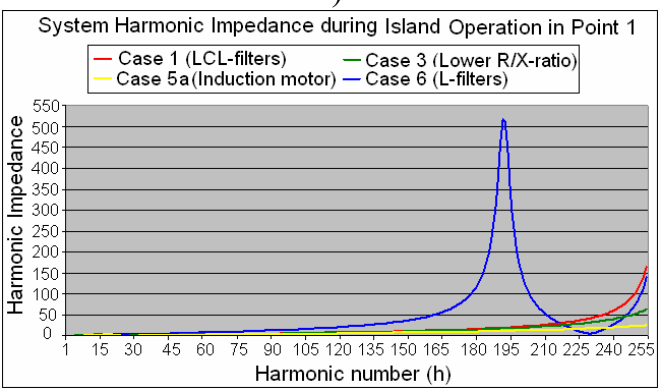

b)

Figure 6. System harmonic impedance during a) normal and $b$ ) island operation of microgrid in cases $1,3,5 a$ and 6 .

\section{The effect of negative sequence filtering on THD}

In addition to the previous simulation results with different microgrid configurations (table 4), the simulation results with cases $5 \mathrm{a}$ and $5 \mathrm{~b}$ (table 1 ) are presented in table 5 . The simulations are done to show the possibility to reduce the microgrid voltage and current THD during unsymmetrical faults and/or unbalanced load by using negative sequence filtering [5] in control system of converters (see Fig. 4). From Fig. 7 the effect of unbalanced load on phase voltages during normal and island operation can be seen.

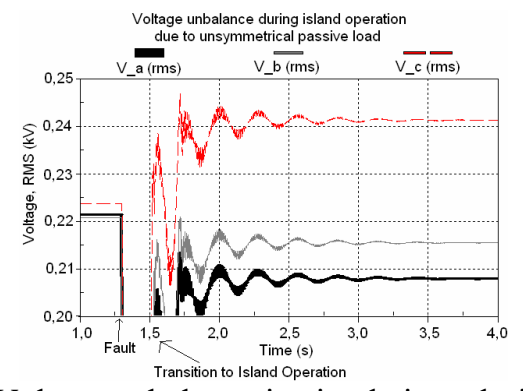

Figure 7. Voltage unbalance in simulations during island operation due to unsymmetrical passive load. 
Table 5. The effect of negative sequence filtering in control system of converters to voltage and current THD (255 harmonics) of microgrid in cases $5 \mathrm{a}$ and $5 \mathrm{~b}$.

\begin{tabular}{|c|c|c|c|}
\hline $\begin{array}{l}\text { Neg. Seq. } \\
\text { filtering }\end{array}$ & $\begin{array}{c}\text { Before } \\
\text { Islanding } \\
\left(\mathbf{U}_{\mathrm{THD}}^{*} / \mathbf{I}_{\mathrm{THD}}{ }^{* *}\right) \\
\end{array}$ & $\begin{array}{c}\text { During Fault }{ }^{* * *} \\
\text { Before Islanding } \\
\left(\mathbf{U}_{\mathrm{THD}}{ }^{*} / \mathbf{I}_{\mathrm{THD}}{ }^{* *}\right) \\
\end{array}$ & $\begin{array}{c}\text { During } \\
\text { Islanding } \\
\left(\mathbf{U}_{\text {THD }}{ }^{*} / \mathbf{I}_{\text {THD }}{ }^{* * *}\right) \\
\end{array}$ \\
\hline 5a. No & $0.41 / 0.27$ & $0.75 / 8.70$ & $1.16 / 0.29$ \\
\hline 5b. No & $0.42 / 0.44$ & $1.01 / 8.90$ & $1.70 / 1.11$ \\
\hline $\begin{array}{c}\text { 5a. With } \\
\text { PLL }\end{array}$ & $0.41 / 0.27$ & $0.54 / 6.1$ & $1.16 / 0.29$ \\
\hline $\begin{array}{l}\text { 5b. With } \\
\text { PLL }\end{array}$ & $0.42 / 0.41$ & $0.81 / 6.23$ & $1.70 / 1.12$ \\
\hline $\begin{array}{l}\text { 5a. With } \\
\text { PLL \& } \mathrm{I}_{\mathrm{ref}}\end{array}$ & $0.41 / 0.27$ & $0.19 / 0.20$ & $1.14 / 0.25$ \\
\hline $\begin{array}{l}\text { 5b. With } \\
\text { PLL \& } I_{\text {ref }}\end{array}$ & $0.41 / 0.28$ & $0.25 / 0.21$ & $1.15 / 0.31$ \\
\hline
\end{tabular}

${ }^{*}$ From phase $\mathrm{C}$ in connection point of master unit, ${ }^{* *}$ From phase $\mathrm{A}$ in connection point of DG Unit 1 on feeder 1_1, ${ }^{* * *}$ Unsymmetrical 2-phase earth fault (A-B-ground) in utility grid

From the simulation results of table 5 it can be seen that the unsymmetrical passive load in case $5 \mathrm{~b}$ increases the voltage and current THD in microgrid especially during islanding when the difference between phase voltage magnitudes (Fig. 7) is larger when compared to case 5a. The negative sequence filtering with PLL can be done to improve the stability of the converter based unit especially during unsymmetrical faults. From simulation results of table 5 one can see that by using negative sequence filtering with PLL the voltage and current THD is slightly reduced in cases $5 \mathrm{a}$ and $5 \mathrm{~b}$. However, when negative sequence is filtered from the current reference $\mathrm{I}_{\text {ref }}$ in converter control system (Fig. 4) the current THD is reduced in case $5 \mathrm{~b}$ during normal operation and also during unsymmetrical fault before islanding the voltage and current THD in cases $5 \mathrm{a}$ and $5 \mathrm{~b}$ is significantly reduced (table 5). In addition, after islanding the distortions in voltage and current are notably lower. However, the negative sequence filtering from current reference $\mathrm{I}_{\text {ref }}$ does not remove the ripple from dc-link voltage during unsymmetrical fault.

\section{CONCLUSIONS}

Based on the simulation results it is obvious that voltage THD behaviour cannot be foreseen from the current THD contribution of the converter when operating normally parallel with utility grid. They are affected by the particular system harmonic impedance in that point and the harmonics coming from other devices (i.e. backround harmonic voltages) which are dependent on the configuration, control system and parameters of these devices. When the microgrid transfers from normal to islanded operation the grid impedances and the harmonic voltages will change. Therefore, during the island operation of the microgrid there is a risk that some higher order harmonics near the switching frequency of the converter may resonate with the changed system harmonic impedance and even without resonances the harmonic currents produced by converters and possible distorting loads will generate much higher harmonic voltages during island operation. Summary about the findings to ensure high power quality in islanded microgrid is presented in Fig. 8.

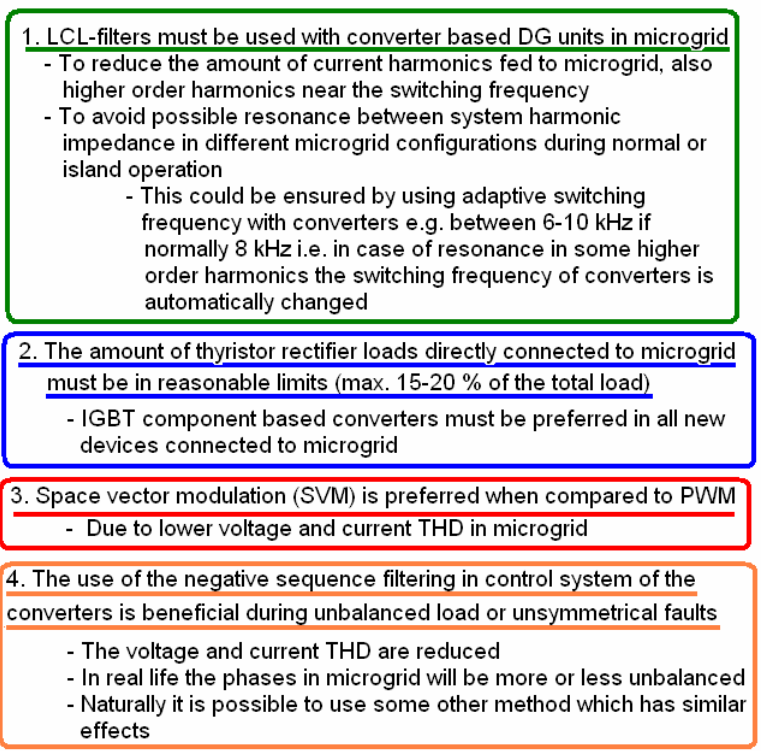

Figure 8. Summary from the findings to ensure high power quality in islanded microgrid.

\section{Acknowledgments}

The authors want to express their thanks to Tekes, the Finnish Funding Agency for Technology and Innovation, and companies for their financial support in Energy storage for managing distributed generation -project which is part of Tekes Distributed energy systems technology programme (DENSY) 2003-2007.

\section{REFERENCES}

[1] R.C. Dugan, M.F. McGranaghan, S. Santoso, H.W. Beaty, 2002, Electrical Power Systems Quality, Second Edition, McGraw-Hill.

[2] H. Laaksonen, K. Kauhaniemi, 2007, "Sensitivity Analysis of Frequency and Voltage Stability in Islanded Microgrid", Proc. 19th International Conference and Exhibition on Electricity Distribution (CIRED), Vienna, Austria.

[3] H. Laaksonen, K. Kauhaniemi, 2007, "Fault Type and Location Detection in Islanded Microgrid with Different Control Methods based Converters", Proc. 19th International Conference and Exhibition on Electricity Distribution (CIRED), Vienna, Austria.

[4] H. Laaksonen, K. Kauhaniemi, 2008, "New Concept for Power Quality Management in Microgrid with Energy Storage Based Power Quality Compensator", International Journal of Distributed Energy Resources (DER Journal), vol. 4 no. 2.

[5] S-J. Lee, J-K. Kang, S-K. Sul, 1999, "A New Phase Detecting Method for Power Conversion Systems Considering Distorted Conditions in Power System", IEEE IAS Annual Meeting, vol. 4, pp. 2167-2172. 